\title{
Capacity Building of Editors of by Higher Education Commission of Pakistan is Commendable Initiative
}

\author{
Shireen Jawed, Benash Altaf, Farah Amir Ali
}

Numerous biomedical journals are currently published in Pakistan and recognized by various regulatory bodies. Out of these renowned medical journals, only three of them meet the criteria of international ranking of medical journals and earned the impact factors (IF), which reflects the high number of citations of their publications. These journals include the Pakistan Journal of Medical Sciences (PJMS), Journal of Pakistan Medical Association (JPMA) and Journal of College of Physicians \& Surgeons Pakistan(JCPSP). ${ }^{1}$ Other Pakistani medical journals are also doing their best efforts for uplifting their journals by improving the standard of publications and shortcomings. On the other hand, those who failed to improve the quality of journals have been derecognized by Higher Education Commission (HEC). There are so many causes of the failure of these journals. ${ }^{2}$ The most important reason being the inexperienced and untrained medical editors who though very enthusiastic for bearing additional burden of difficult unrewarding task. Lack of guidance, knowledge, proper training, mentoring and limited financial revenue are also the factors contributing for a medical journal failure to reach the target set by HEC. Moreover, editors also experience the difficulty finding the proper subject specific expert reviewer in order to improve the manuscript intellectual content. In the same way, authors are also crucially important who are responsible for the manuscript but usually fails to comply with the COPE guidelines for author. Professionalism, following transparent policies, functional editorial boards and experienced reviewers helps in improving the standards of medical journals, reducing the pressure on the medical editors of reputable journals. Hence, professional trainings are needed to improve the multidisciplinary domains of medical journalism for improving the quality and authenticity of the published work. ${ }^{3}$

In this regard, efforts of Higher Education Commission Pakistan (HEC) are commendable for improving the standards of research journals and promoting Professionalism in scientific editing through edification

\section{Correspondence:}

Dr. Shireen Jawed

Email: journal.editor@afmdc.edu.pk capacity building, mentoring and financial support of research journals. HEC has set the new criteria to raise the quality of national research journals to meet the international standards. For this purpose, HEC has promulgated revised journal recognition policies for the provision of a transparent system for accreditation. Moreover, HEC has been extending financial assistance to its recognized journals in numerous disciplines including medical sciences to support and overwhelmed their financial problems, which is creditable. $^{2}$

HEC has introduced an online system entitled "HEC Journal Recognition System (HJRS)"for accreditation of journals. For assuring effective productivity and quality of journals they are evaluated based on six international benchmark matrices instead of using a single measure of journal impact factor depending on Journal citation report (JCR). ${ }^{4}$ These matrices including Eigen Factor (EF), Article Influence (AIF), H index, citation per doc, Scimago, Journal Rank (SJR) and Source Normalized Index per Paper (SNIP). Using these matrics, journal prestige index (JPI) is computed for categorization of research journals into $\mathrm{W}, \mathrm{X}$, and $\mathrm{Y}$ categories. ${ }^{5}$ Strengthening the capacities of authors, editors, as well as reviewers are mandatory for uplifting the research Journals. HEC is making persistent efforts for facilitating and training all stakeholders for enhancing knowledge and skills to address the root issues of problems, thereby ensuring the lasting results. HEC in collaboration with local and international organizations is also been arranging several meetings, studios and webinars for editorial guidance, that is helping the editors of national research journals, trying to bring them up to the international levels. To endeavor this goal, the Research and Development Department (R\&D) of HEC has conducted an online comprehensive series of capacity building program for the editors of research journals. ${ }^{6}$ These sessions were quite informative and covering all the required aspects including publication processing, peer review, editorial workflow and responsibilities of the editorial team. Advantages of various tools like Turnitin iThenticate for checking plagiarism and the use of publon for searching international reviewers for provision of constructive review and standard articles. All key points were discussed in these valuable sessions. Furthermore, editors were guided about prerequisites and procedures for indexing with various 
international databases like a directory of open access journals (DOAJ), web of science and Scopus for better visibility.The sessions about requirements of antipredatory agencies like the conduct of publication ethic (COPE) was helpful and informative for making the individual journal new policies according to guidelines. Dealing with authorship issue and any type of publication misconduct including plagiarism, falsification, and fabrication remained the part of discussion. The session concerning guidance about how to register with COPE and how to avoid enlistment in Beall's list and Cabell's Predatory Reports were also prove helpful for editors. Points for avoidance for removal from DOAJ list and other data bases has been discussed in sessions. The orientation of the HJR system was also part of these sessions. Session on use of open journal system for transparent handlings of an article and to improve the visibility of published research articles was also helpful and informative. Hence all the session being arranged by $R \& D$ department were helpful in capacity building of editors. ${ }^{6}$ Hopefully, efforts of the R\&D team under the supervision of Director Dr. Muhammad Tahir Ali Shah in capacity building of the entire editorial team of national research journals will be fruitful and plays a key role in the flourishing of these medical journals, ensuring the publication of the best quality research work up to the international standards. Our request in this aspect to HEC is to provide opportunity to recognize the newly launched medical journals so that they get motivated to further enhance the quality of their journals based on laid down policies of HEC. Once again we are thankful to HEC for its facilitation provided in form of capacity building which truly helped us to improve the quality of our journal.

\section{REFERENCES}

1. Jawaid SA, Jawaid M. Impact Factor is Off the Ventilator: Survives and is Thriving. Pak J Med Sci. 2018; 34(6): 1317 1319doi:10.12669/pjms.346.16652

2. Jawaid SA, Jawaid M. Revised publication policies by higher education commission for health science journals. Pak J Med Sci.2020;36(2):13.doi:10.12669/pjms.36.2.2133.

3. Jawaid SA, Jawaid M. Professional competencies required for Editors of Biomedical Journals. Pak J Med Sci. 2017 ;33(5):10501052.doi:10.12669/pjms.335.13967

4. HEC Journal recognition system. https: //hjrs.hec.gov.pk/ index php?r=site\%2Fabout [ cited on: Feb16,2021]

5. HEC Journal recognition system. https://hjrs.hec.gov.pk/ [cited on : Feb 17,2021]

6. Research section and publication division. Capacity Building Program me for the Year 2020-21. .https ://hec. gov.pk /english/HEC nnouncements/Documents/Brochure-Research Journals pdf [ cited on: Feb 17,2021]

\section{Conflict of interest: None}

